Original Research Paper

\title{
Penyuluhan Strategi Konservasi dan Pengembangan Ekowisata Mangrove di Desa Mertak Sebagai Daerah Penyangga KEK Mandalika Lombok Tengah
}

\author{
Lalu Zukifli ${ }^{1}$, Abdul Syukur ${ }^{1}$, Agil Al Idrus ${ }^{1}$, Mahrus ${ }^{1}$

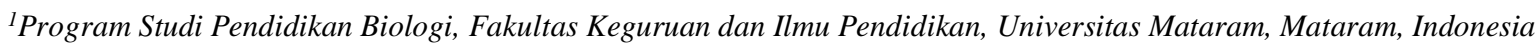

DOI: https://doi.org/10.29303/jpmpi.v3i2.573

Sitasi:. Zulkifli. L.,Syukur, A., Idrus, A. A., \& Mahrus. (2020). Penyuluhan Strategi Konservasi dan Pengembangan Ekowisata Mangrove di Desa Mertak Sebagai Daerah Penyangga KEK Mandalika Lombok Tengah. Jurnal Pengabdian Magister Pendidikan IPA, 3(2)

\section{Article history}

Received: 25 Oktober

Revised: 15 Nopember

Accepted: 30 Desember

*Corresponding Author: Lalu

Zukifli, Program Studi

Pendidikan Biologi, Fakultas

Keguruan dan Ilmu Pendidikan

Universitas Mataram, Mataram,

Indonesia

Email:

lalu_zulkifli@unram.ac.id

\begin{abstract}
Desa Mertak adalah desa pantai yang memiliki potensi wisata alam dan masuk dalam wilayah pengembangan ekonomi khusus Mandalika di Kabupaten Lombok Tengah. Untuk meningkatkan peran serta Masyarakat Desa Mertak Maka Tim Pengabdian menginisiasi Program pengabdian pada masyarakat yang terkait langsung dengan pemberdayaan potensi wisata alam di Desa Mertak khususnya pengembangan areal pantai Dusun Semunduk. Berkaitan dengan hal diatas tim pengabdian melakukan sosialisasi dan strategi konservasi dan pengelolaan hutan mangrove dengan Metode ceramah dan diskusi yang dilanjutkan dengan kegiatan penanaman mangrove. Hasil kegiatan menunjukkan bahwa Pelaksanaan program pengabdian masyarakat di Dusun Semunduk dan Dusun Mertak Desa Mertak, Kecamatan Pujut Lombok Tengah telah berhasil dilakukan dengan baik. Hal ini terlihat dari antusias anggota masyarakat pada saat ceramah dan diskusi. Pada saat tahap penanaman bibit juga mereka bergotong royong melakukan penanaman sesuai dengan yang diarahkan Tim pengabdian. Diharapkan pengabdian ini dapat memberikan pengetahuan dan memberikan pemahaman dan keterampilan kepada masyarakat lokal bahwa Desa Mertak memiliki peran penting sebagai penyangga KEK Mandalika di masa yang akan datang.
\end{abstract}

Keywords: Konservasi Mangrove; Ekowisata; KEK Mandalika; Desa Mertak.

\section{Pendahuluan}

Desa Mertak adalah salah satu desa secara administratif masuk dalam wilayah Kecamatan Pujut dan kawasan Daerah Penyangga KEK Mandalika Lombok Tengah. Selanjutnya, wilayah pesisir selatan Kecamatan Pujut dan di dalamnya adalah Desa Mertak memiliki luas 4514, 52 ha $(19,33 \%)$ dari luas wilayah Kecamatan Pujut. Desa Mertak adalah Desa Pantai secara administratif masuk dalam wilayah Kecamatan Pujut, jarak lokasi dengan Universitas Mataram adalah $\pm 50 \mathrm{~km}$. Potensi lingkungan pesisir yang masih relatif alami dengan kekhasan keindahan pantai, telah menjadikan kawasan selatan Kecamatan Pujut menjadi tujuan wisata utama di
Pulau Lombok. Desa Mertak sebagai bagian dari tujuan wisata memiliki luas $1427 \mathrm{Ha}$ dengan jumlah penduduk 7.662 (Kecamatan Pujut dalam Angka 2019). Desa Mertak sebagai desa wisata telah memiliki infrastruktur restoran dan fasilitas lain yang cukup memadai, seperti jalan yang relatif sudah baik. Selanjutnya, waktu yang diperlukan untuk mencapai Desa Mertak dari Bandara Internasional Lombok \pm 1 jam. Posisi Desa Mertak dari desa Kuta sebagai lokasi inti KEK Mandalika (Gambar 1.)

Desa mertak memiliki potensi obyek wisata yang berbeda dengan lokasi desa lain di pantai selatan Lombok Tengah. Obyek wisata yang dimaksud adalah wisata alam hutan Gunung Tunak yang merupakan kawasan hutan konservasi dengan 
luas \pm 1200 hektar. Potensi obyek wisata lain di Desa Mertak adalah pantai Semunduk yang merupakan wilayah bagian timur dari Wilayah Kawasan Ekonomi Khusus (KEK) Mandalika. Kawasan wisata pantai di wilayah Desa memiliki dua obyek wisata utama yaitu obyek wisata pantai dan obyek wisata mangrove.

Desa Mertak sebagai kawasan KEK telah menjadi desa binaan Universitas Mataram melalui program Kuliah Kerja Nyata $(\mathrm{KKN})$. Fokus program KKN mahasiswa adalah KKN tematik pariwisata dan produk olahan (Aditama \& Husni, 2019). Namun demikian, waktu KKN yang cukup terbatas menyebabkan beberapa program yang mendukung wisata belum dapat dikerjakan. Hasil diskusi dengan Kepala Desa dan Karang Taruna Desa Mertak pengembangan wisata yang perlu mendapat perhatian khusus adalah wisata mangrove. Selanjutnya dijelaskan bahwa pengembangan wisata mangrove diharapkan dapat membantu mata pencaharian masyarakat Desa Mertak yang masih $60 \%$ kepala keluarga berada pada tingkat prasejahtera dan sejahatra 1 dari 3022 kepala keluarga (Kecamatan Pujut dalam Angka 2019).

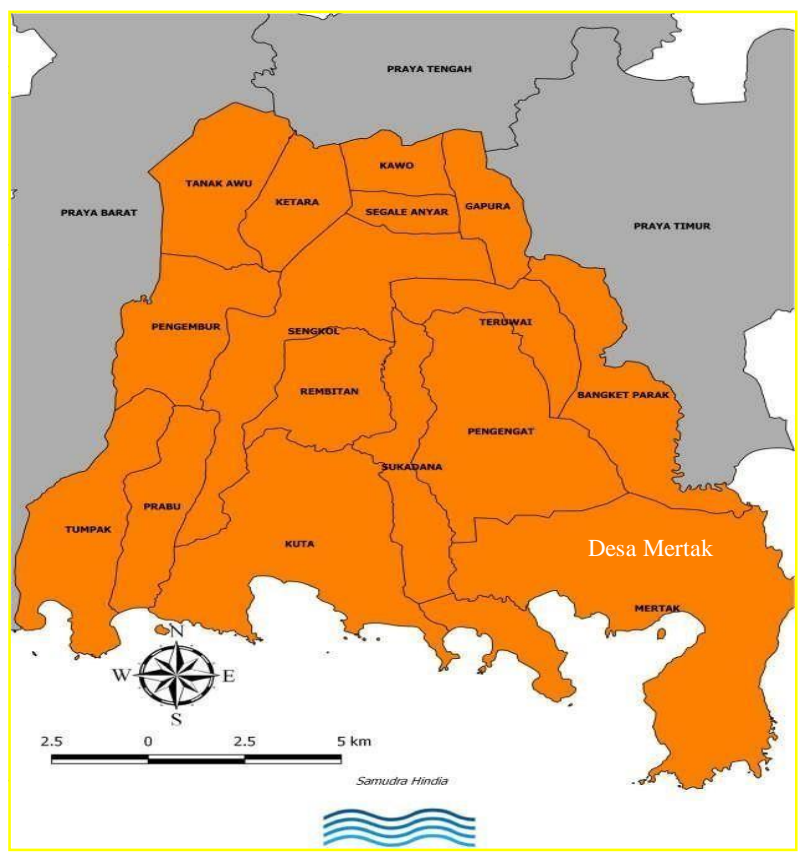

Gambar 1. Lokasi Inti KEK Mandalika

Program konservasi mangrove di Desa Mertak dapat dilakukan melalui dua program yaitu (1) penanaman mangrove dan (2) penyusunan Awik-awik pengelolaan objek wisata. Namun demikian, regulasi berupa Awik-awik pembuatannya telah dilakukan oleh Mahasiswa KKN Tematik Unram. Oleh karena itu, program penanaman mangrove adalah menjadi fokus dari Tim Pengabdian pada masyarakat dengan skema kemitraan. Program penanaman mangrove adalah sebagai sarana rekayasa sosial untuk meningkatkan kesadaran masyarakat tentang nilai konservasi mangrove untuk kelestarian biota laut dan mata pencaharian masyarakat lokal. ekonomi. Dalam hal ini, sumber daya hutan mangrove telah memberikan kontribusi penting bagi mata pencaharian masyarakat lokal (Idrus et al., 2019). Selanjutnya dijelaskan, pemanfaatan jasa mangrove adalah strategi pemanfaatan untuk mencapai tujuan konservasi dan diversifikasi mata pencaharian masyarakat lokal. Selain itu, penanaman mangrove memiliki dampak positif pada pemulihan kondisi lingkungan kondisi, seperti keanekaragaman fauna dan tingkat keberhasilan penanaman mangrove dapat mencapai 80\% (Idrus et al., 2019).

Oleh karena itu,diperlukan program pengabdian dengan skema kemitraaan dengan topik "Penyuluhan Strategi Konservasi dan Pengembangan Ekowisata Mangrove di Desa Mertak Sebagai Daerah Penyangga KEK Mandalika Lombok Tengah.

\section{Metode}

\section{Persiapan}

Rencana program pengabdian pada masyarakat di Desa Ketapang Raya tentang pengembangan objek wisata baru sebagai sumber mata pencaharian masyarakat berbasis ekowisata, dalam ha ini TIM pengabdian akan mempersiapkan beberapa hal yang meliputi materi, konsolidasi dengan pemerintah desa, mitra dan masyarakat sebagai kelompok sasaran dari kegiatan pengabdian pada masyarakat.

\section{Pelaksanaan}

Pengembangan ekowisata di Desa Desa Ketapang Raya berdasarkan solusi dari permasalahan seperti yang telah diuraikan diatas membutuh metode pelaksanaan yang relevan. Beberapa metode yang akan digunakan adalah:

1. Sosialisasi, pada tahap ini Tim mensosialisasikan tema program pada tokoh masyarakat dan stakeholder lainnya. Metode yang digunakan adalah diskusi/FGD. Tujuan pada program sosialisasi adalah untuk 
memperoleh pemahaman yang sama tentang pentingnya mangrove sebagai obyek ekowisata dan sumber mata pencaharian masyarakat di Desa Mertak. Dalam hal ini, materi terdiri dari: (a) Uraian yang menjelaskan tentang fungsi ekosistem mangrove, dan bagaimana pengembangannya sebagai obyek ekowisata mangrove di Desa Mertak sebagai daerah penyangga dalam mendukung KEK Mandalika; (b). Uraian yang menjelaskan tentang tahapan dalam proses konservasi mangrove.

2. Penanaman mangrove menggunakan metode partisipasi masyarakat dengan teknik penanaman yang disesuaikan dengan kondisi lingkungan.

\section{Hasil dan Pembahasan}

\section{Analisa Hasil}

Pada tahap sosialisasi ini masyarakat Dusun Semunduk dam dusun Mertak yang hadir mencapai 30 orang (Gambar 2). Pada saat penyuluhan dan diskusi, mereka sangat antusias dalam mendengarkan materi. Kadus dan beberapa tokoh masyarakat meminta agar program sosialisasi dan penanaman dapat dilakukan secara continue. Hal ini diperlukan agar masyarakat terus dapat terlibat dan ada motivasinya dalam menjaga hasil penanaman yang dilakukan. Setelah pelaksanaan kegiatan ini, masyarakat di Desa Mertak khusus Dusun Semunduk dan Dusun Mertak Kabupaten Lombok Tengah mendapatkan gambaran pentingnya hutan mangrove yang dapat sebagai salah satu aspek yang dapat dikembangkan ke depan yang dapat dapat berperan dalam mendukung mata pencaharian dan menyadari bahwa Desa Mertak adalah bagian penting dalam mendukung pengembangan kawasan KEK Mandalika.

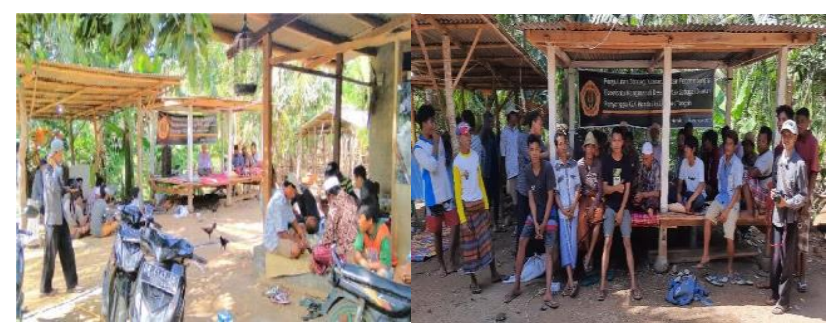

Gambar 2. Dokumentasi saat ceramah dan diskusi tentang pentingnya strategi konseravasi ekosistem mangrove dan kaitannya dengan pengembangan ekowisata mangrove di Desa Mertak sebagai daerah penyangga KEK Mandalika.

\section{Penanaman mangrove di areal pantai Dusun Semunduk.}

Penanaman bibit mangrove dilakukan di daerah pantai Dusun Semunduk yang substratnya agak tebal. Spesies mangrove yang ditanam adalah Rhizophora apiculata. Bibit dibeli dari Daerah Pantai Cemare Lombok Barat. Bibit ini sudah berusia 4 bulan sehingga cukup baik untuk penanaman. Bibit yang ditanam diperkuat dan diikat dengan bilahan bambu yang ditanam sampai minimal $60 \mathrm{~cm}$ ke dalam substrat agar bibit tetap kuat pada saat pasang surut, sehingga akar tidak terganggu. Hal ini dimaksudkan bibit dapat bertahan dan tumbuh dengan baik.

Pada saat penanaman ini partisipasi masyarakat sangat baik dengan bergotong royong bersama sama mengangkut bibit bahan tanam dan alat-alat perlengkapan untuk menanam bibit mangrove. S (Gambar 3).

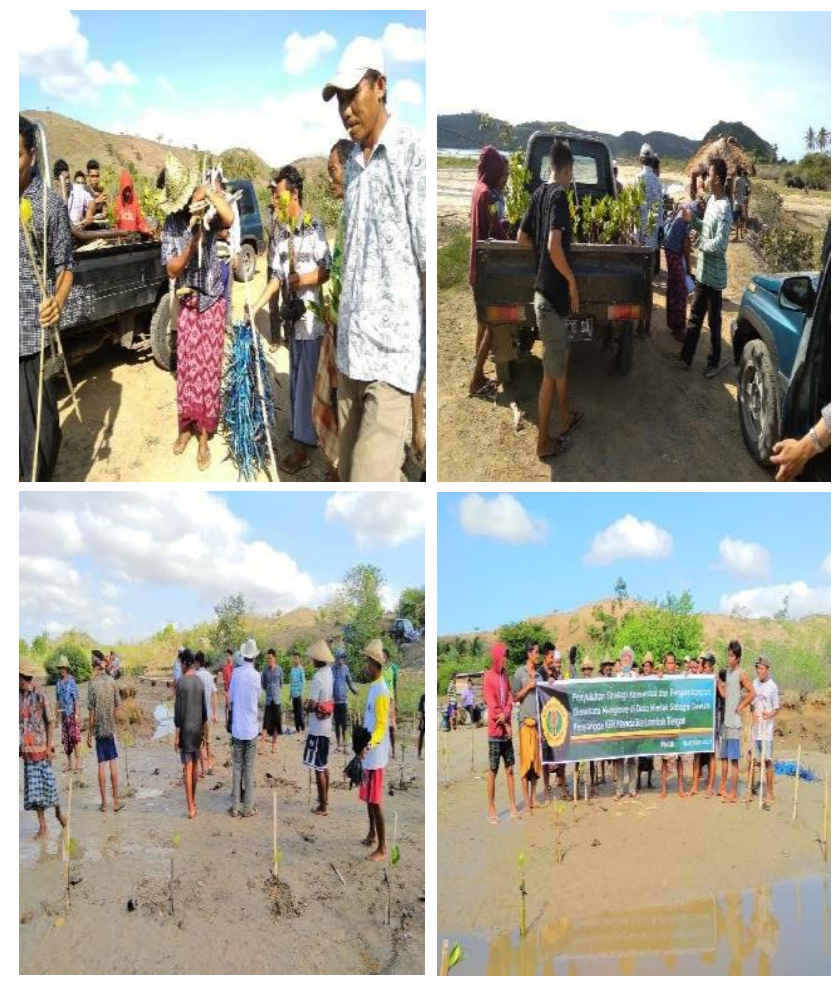

Gambar 3. Partisipasi masyarakat pada kegiatan penanaman bibit mangrove di daerah pantai Dusun Semunduk Desa Mertak, Kecamatan Pujut, Lombok Tengah.

\section{Faktor Pendorong}

Setelah diberikan ceramah dan diskusi maka masyarakat menjadi paham akan penting 
konservasi mangrove, apalagi mereka mengetahui status hutan mangrove di daerahnya ke depan dapat dikembangkan sebagai salah satu situs untuk wisata hutan mangrove. Hal ini menjadi salah satu faktor penting dalam membantu meningkatkan pendapatan mereka di masa yang akan datang, bahwa hutan mangrove penting sebagai tempat berkembangbiaknya berbagai macam ikan dan organisme laut yang penting untuk kehidupan sehari-hari.

\section{Faktor Penghambat}

Dalam pelaksanaan kegiatan ini, Tim tidak mendapatkan faktor penghambat dalam sosialisasi dan kegiatan penanaman mangrove. Diharapkan setelah penanaman ini masyarakat ikut menjaga agar bibit tumbuh dengan baik.

\section{Kesimpulan}

Pelaksanaan program pengabdian masyarakat di Dusun Semunduk dan Dusun Mertak Desa Mertak, Kecamatan Pujut Lombok Tengah telah berhasil dilakukan dengan baik. Hal ini terlihat dari antusias anggota masyarakat pada saat ceramah dan diskusi. Pada saat tahap penanaman bibit juga mereka bergotong royong melakukan penanaman sesuai dengan yang diarahkan Tim pengabdian. Program ini ke depan perlu perkuat dan ditindaklanjuti pada skala yang lebih besar dengan mengintegrasikannya dengan program pengembangan wisata bahari di Desa Mertak dengan kerjasama dari lembaga terkait misalnya pemda, pihak perguruan tinggi dan lembaga swadaya masyarakat dalam menciptakan fungsi Desa Mertak sebagai penyangga pengembangan KEK Mandalika.

\section{Ucapan Terima Kasih}

Penulis mengucapkan terima kasih kepada Rektor Universitas Mataram yang telah memberi dukungan finansial terhadap pengabdian ini.

\section{Daftar Pustaka}

Aditama, F. A., \& Husni, S. (2019). Pengelolaan Objek Wisata Pantai Bumbang Berbasis Masyarakat di Desa Mertak Kecamatan Pujut Kabupaten Lombok Tengah. Jurnal Warta Desa, 1(2).
Idrus, A. A., Syukur, A., \& Zulkifli, L. (2019). The diversity of fauna in mangrove community: Success replanting of mangroves species in South Coastal East Lombok, Indonesia. In Journal of Physics: Conference Series (Vol. 1402, No. 3, p. 033042). IOP Publishing.

Idrus, A. A., Syukur, A., \& Zulkifli, L. (2019, December). The livelihoods of local communities: Evidence success of mangrove conservation on the coastal of East Lombok Indonesia. In AIP Conference Proceedings (Vol. 2199, No. 1, p. 050010). AIP Publishing LLC.

Kecamatan Pujut dalam Angka 2019. 